\title{
HAORNAS: GERAKAN SPORT FOR ALL KUNCI KEBERHASILAN OLAHRAGA INDONESIA
}

\author{
Adi Rahadian ${ }^{1 *}$, Amung Ma'mun ${ }^{2}$, Berliana $^{3}$, Nuryadi $^{4}$, Toho Cholik Mutohir ${ }^{5}$ \\ Djoko Pekik Irianto ${ }^{6}$
}

${ }^{1 *}$ Universitas Pendidikan Indonesia, Indonesia, email: adirahadian@upi.edu

${ }^{2}$ Universitas Pendidikan Indonesia, Indonesia, email: amung@upi.edu

${ }^{3}$ Universitas Pendidikan Indonesia, Indonesia, email: berliana@upi.edu

${ }^{4}$ Universitas Pendidikan Indonesia, Indonesia, email: nuryadi_fpok@upi.edu

${ }^{5}$ Universitas Negeri Surabaya, Indonesia, email: tohocholik@unesa.ac.id

${ }^{6}$ Universitas Negeri Yogyakarta, Indonesia, email: djokopekik@uny.ac.id

*Koresponden penulis

\section{Info Artikel}

\section{Diajukan: -}

Diterima: -

Diterbitkan: -

Keyword:

Indonesia; Movement; National Sports Day; Sport for All;

Succsess

Kata Kunci:

Gerakan; Haornas; Indonesia;

Keberhasilan; Sport for All

\begin{abstract}
Haornas is a momentum for sporting success, which is described as a symbol of national revival and sports champions become national icons. This is a sports culture that is carried out in a coherent, integrated and sustainable manner. The purpose of this research is to describe and reveal the history related to the history of Haornas journey and the development of sports in Indonesia. A qualitative approach with exploratory descriptive was chosen in this study. The participants were 8 respondents, consisting of public officials, academics, athletes, and the public, which were taken using qualitative purposive sampling technique. The location is in the DKI Jakarta and West Java areas, the implementation is in July-August. Semi-structured observations and interviews were used in data collection. This finding shows that sporting efforts for all, integrate the path of coaching and sport development in Indonesia which leads to a paradigm shift from 'sports development' to 'development through sport. Thus, sport as an instrument of development that has the potential to improve the quality of life of the Indonesian people. So, the Haornas commemoration with the "sport for all" movement needs to be developed into a sports culture generator in the country.
\end{abstract}

\begin{abstract}
Abstrak
Haornas merupakan momentum keberhasilan olahraga, yang digambarkan sebagai simbol kebangkitan nasional dan juara olahraga menjadi ikon nasional. Hal ini merupakan pembudayaan olahraga yang dilakukan secara koheren, terpadu, dan berkesinambungan. Tujuan dari penelitian ini adalah untuk mendeskripsikan serta mengungkap sejarah yang berkaitan dengan catatan perjalanan Haornas beserta perkembangan olahraga di Indonesia. Pendekatan kualitatif dengan deskriptif eksploratif dipilih dalam penelitian ini. Partisipan berjumlah 8 responden, terdiri dari pejabat publik, akademisi, atlet, dan masyarakat, yang diambil dengan menggunakan teknik qualitative purposive sampling. Lokasi bertempat di wilayah DKI Jakarta dan Jawa Barat, pelaksanaan pada bulan Juli-Agustus. Observasi dan wawancara semi terstruktur digunakan dalam pengumpulan data. Temuan ini menunjukkan bahwa upaya olahraga untuk semua, mengintegrasikan jalur pembinaan dan pengembangan olahraga di Indonesia yang mengarah kepada pergeseran paradigma dari 'pengembangan olahraga' menjadi 'pengembangan melalui olahraga. Dengan demikian, olahraga sebagai instrumen pembangunan yang
\end{abstract}




\section{PENDAHULUAN}

Olahraga merupakan rangkaian aktivitas gerak yang bermanfaat menjadi fondasi dasar dalam meningkatkan kualitas hidup suatu bangsa. Sesuai dengan isu terkini dan karakteristik tema dari penelitian ini, yaitu menelaah kembali sikap pandang dari semboyan atau gerakan "sport for all", dimana keberadaannya masih relevan untuk dijadikan kebaharuan dasar pijakan dalam pembangunan keolahragaan nasional, sekaligus sebagai pemantik peringatan Hari Olahraga Naional (HAORNAS). Jika dicermati lebih lanjut secara mendalam, substansi UU SKN No. 3 Tahun 2005 sesungguhnya sudah terwadahi dalam ruang lingkup dan batasan yang jelas mengenai pembinaan dan pengembangan olahraga di Indonesia. Hal itu diperkuat dengan beberapa penelitian, diantaranya tatanan sistem olahraga (Hong, Wu, \& Xiong, 2005), kompetisi yang berkelanjutan (Kidd, 2008), efektivitas kebijakan olahraga (de Bosscher, Shilbury, Theeboom, van Hoecke, \& de Knop, 2011), sistem penghargaan (Veal, 2011), strategi dan jalur pengembangan olahraga (Sotiriadou, 2013), efisiensi program latihan (Gulbin, Croser, Morley, \& Weissensteiner, 2013), kebijakan pemerintah (Funahashi, De Bosscher, \& Mano, 2015), alokasi pendanaan (Hu \& Henry, 2017), pengelolaan kebijakan olahraga (Sotiriadou \& De Bosscher, 2018), kesejahteraan atlet (Brown, Arnold, Reid, \& Roberts, 2018), menumbuhkan budaya olahraga di Indonesia (Ma'mun, 2019), dan keberhasilan olahraga merupakan simbol kebangkitan nasional dan juara olahraga menjadi ikon nasional (Rahadian, Ma'mun, Berliana, \& Nuryadi, 2021b).

Sementara itu, penelitian ini betujuan mengungkap persoalan yang terletak pada belum terwujudnya pembangunan olahraga yang terintegritas (Molan, Kelly, Arnold, \& Matthews, 2019) menjadi satu kesatuan. Sehingga menjadikan permasalahan, momentum Hari Olahraga Nasional (HAORNAS) sebagai representasi hasil refleksi dari pencapaian prestasi olahraga nasional. 
Pemberdayaan sentra-sentra, klub-klub, dan sanggar-sanggar olahraga di daerah merupakan hulu pembinaan dan pengembangan olahraga. Dari sana timbul budaya olahraga, yang berujung menjadi bibit-bibit potensial untuk mengangkat kehormatan bangsa. Dengan kata lain, partisipasi akan memfasilitasi terbentuknya prestasi di masyarakat. Oleh karena itu, stake holder yang terkait berfokus utama untuk mengotimalkan tugas dan wewenangnya dalam upaya pembinaan dan pengembangan keolahragaan nasional.

Kondisi yang terjadi di lapangan menunjukkan, diantaranya: 1) belum jelasnya arah pembangunan keolahragaan nasional, yang mengakibatkan angka partisipasi dan budaya olahraga masih rendah; 2) pembinaan dan pengembangan olahraga yang belum sitematis, terpadu, dan berkelanjutan; 3) aksesbiltas dan fasilitas olahraga yang masih minim; dan 4) fluktasi pencapaian prestasi Indonesia di ajang internasional. Membangun olahraga bermakna membangun sebuah peradaban masyarakat yang mengedepankan keunggulan obyektif, kompetitif, dan sportivitas. Berdasarkan hal tersebut, perwujudan dari membangun olahraga berarti membangun segala sesuatu yang terkait dengan dimensi lengkap keunggulan kehidupan masyarakat (Kristiyanto, 2016).

Dari penjelasan di atas, dasar kebijakan pemerintah sebagai regulasi penyelenggaraan keolahragaan nasional dan teori yang dijelaskan oleh para ahli merupakan sebuah konsep yang ideal, namun dengan kondisi yang terjadi di lapangan terdapat kesenjangan atau gap research. Oleh karena itu, penguatan gerakan aktivitas olahraga melalui sport for all dilakukan sebagai solusi yang efektif dalam upaya menggugah kembali kesadaran masyarakat untuk berolahraga sebagai bagian integral dari kehidupan sehari-harinya, sehingga olahraga menjadi budaya (life style). Jika dicermati lebih lanjut, potensi olahraga dimanifestasikan sebagai penopang dalam upaya memperkokoh karakter unggul sebagai sebuah bangsa yang berproses meningkatkan kualitas hidupnya. Dengan demikian, budaya olahraga menjadi partisipasi masyarakat yang memberikan dampak luar biasa dalam menopang kemajuan olahraga, serta merupakan bagian yang tidak terpisahkan dari sport for all atau olahraga untuk semua. 


\section{METODE}

Penelitan kualitatif dengan metode deskriptif ekploratif yang mencakup tentang gerakan "sport for all" kunci keberhasilan olahraga Indonesia sebagai upaya pembangunan keolahragaan nasional. Partisipan dalam penelitian ini berjumlah 8 responden, yang terdiri dari pejabat publik, akademisi, atlet, dan masyarakat yang diambil dengan menggunakan teknik qualitative purposive sampling (Creswelll, 2015). Lokasi penelitian bertempat di wilayah DKI Jakarta dan Jawa Barat, yang dilaksanakan pada bulan Juli-Agustus. Selanjutnya, pengumpulan data dalam penelitian ini dilakukan melalui teknik pengumpulan data pada observasi dan wawancara (semi-terstruktur) dengan berfokus pada jenis data aktual dalam prosedur pengumpulannya, dan mengantisipasi persoalan etik yang mungkin muncul (Creswelll, 2015). Analisis data melalui kategori-kategori yang dibuat secara koding. Tahap akhir dari analisis data ialah mengadakan pemeriksaan keabsahan data yang disebut dengan triangulasi, yaitu pada tahap ini dilakukan pengecekan kebenaran data (credibility, transferability, dependability, dan confirmability). Setelah selesai tahap ini, mulailah kini pada tahap penafsiran data dalam mengolah hasil sementara menjadi teori substansif dengan menggunakan teknik pengolahan dan analisis data Nvivo 12 Plus.

\section{HASIL DAN PEMBAHASAN}

\section{Analisa faktual berdasarkan perjalanan peristiwa dan sejarah HAORNAS}

Membangun identitas bangsa Indonesia melalui olahraga dijadikan dasar utama pendukung pembangunan sebuah bangsa (Lutan, 2005). Soekarno menggunakan kerangka pikir 'nation and character building' untuk menanamkan rasa kemajuan, meskipun ada kesulitan lain, terutama yang berkaitan dengan ekonomi (Zhouxiang, 2011). Dengan demikian makna nation and character building dalam konteks pembangunan olahraga dapat dipersepsikan sebagai pembentukkan manusia Indonesia agar unggul dalam tatanan berpikir (intelektual), fisikal, mental-emosional-sosial, beretika moral, berkepribadian, 
berintegritas, berwatak, berperilaku adil, mencintai perdamaian dan terpuji, serta memiliki kecintaan dan kebanggaan yang amat kuat akan ke-Indonesiaan atau kebangsaan Indonesia (Ma'mun, 2019). Berdasarkan hal tersebut, olahraga dapat dijadikan sebagai satu media yang efektif untuk saling mempererat hubungan antar bangsa dalam suasana persahabatan dan persamaan derajat (Zhang, Hong, \& Huang, 2018).

Berbagai peritiwa yang terjadi dalam perjalan keolahragaan nasional, baik di yang terselenggara di dalam maupun luar negeri. Hal ini seiring dengan gerakan pengembangan olahraga internasional, yang gaungnya terkenal dengan semboyan "sport for all". Upaya yang sama dilakukan Soeharto, momentum kebangkitan keolahragaan nasional dilakukan melalui pembinaan bangsa dan pembangunan negara, meliputi kegiatan pendidikan jasmani dan olahraga sebagai bagian usaha untuk membangun manusia Indonesia yang utuh (jasmaniah dan rohaniah). Dengan semboyan "memasyarakatkan olahraga dan mengolahragakan masyarakat", diharapkan akan berkembang menjadi suatu gerakan keolahragaan nasional yang terpadu.

Semangat Penetapan Hari Olahraga Nasional (HAORNAS), diawali dari PON I yang mengusung gerakan pembangunan olahraga dalam rangka mewujudkan identitas diri kebangasaan untuk memperkokoh sikap pandang bangsa tentang eksistensi sebagai negara yang baru merdeka kepada dunia internasional. Hal ini, merupakan perjalanan tonggak sejarah persatuan dan kesatuan yang berkaitan erat dengan perkembangan olahraga nasional di tanah air. Dalam peristiwa ini juga, terjadi pelatakan dasar yang kokoh tentang perkembangan keolahragaan nasional. Diantaranya ditandai dengan lahirnya organisasi dari berbagai cabang olahraga yang kemudian tergabung dalam federasi olahraga internasional (Khusniani, 2020).

Adapun pemaparan mengenai fakta-fakta Hari Olahraga Nasional (HAORNAS), yaitu penentuan tanggal 9 September diambil dari sejarah tanggal penyelenggaraan PON (Pekan Olahraga Nasional) yang pertama kalinya diadakan di Solo, Jawa Tengah, pada tahun 1949. Berdasarkan rangkaian 
peristiwanya, PON memiliki dampak menguntungkan pada gerakan menuju kemerdekaan dan kebangsaan (Adams, 2002). Kemudian pada tanggal 16 Mei 1983, Sri Sultan Hamengku Buwono IX mengusulkan ajuan tanggal 10 September sebagai Hari Olahraga Nasional (HAORNAS). Selanjutnya, pada Hasil Sidang KONI XIII yang dilaksanakan tanggal 17 Mei 1983 menetapkan hasil bahwa tanggal 8 September sebagai Hari Olahraga. Yang pada akhirnya 9 September 1983, Presiden Soeharto mencanangkan tanggal 9 September sebagai Hari Olahraga Nasional (HAORNAS). Kemudian penetapan tersebut tertuang dalam Keputusan Presisden (Kepres) No. 67 Tahun 1985 tentang Hari Olahraga Nasional (HAORNAS). Dalam Keppres tersebut disebutkan bahwa penetapan Hari Olahraga Nasional (HAORNAS) berhubungan dengan peningkatan, pembinaan, dan perkembangan olahraga secara berlanjut.

Pencanangan Hari Olahraga Nasional disambut positif oleh berbagai pihak, hal ini dianggap sebagai langkah konkret pemerintah untuk mendorong keolahragaan di Tanah Air. Sehingga dalam kerangka pembangunan olahraga memiliki arti luas, bukan tentang pertandingan demi sebuah prestasi atau medali. Oleh karena itu, momentum peringatan Hari Olahraga Nasional (HAORNAS) dimaknai sebagai titik tolak reorientasi dalam upaya menentukan hasil berdasarkan faktor kontekstual, proses, dan spesifikasi (Rahadian et al., 2021b). Dengan kata lain, Hari Olahraga Nasional (HAORNAS) bukan hanya suatu peristiwa, melainkan sebuah kegiatan yang sistematis, terpadu dan berkelanjutan. Momentum peringatan Hari Olahraga Nasional (HAORNAS) merupakan legacy yang perlu inovasi dengan berbagai program mutakhir. Hal tersebut sebagai upaya untuk mendukung kebijakan pemerintah dalam pelayanan publik berkenaan dengan keolahragaan nasional (Rahadian \& Ma'mun, 2018).

Bersamaan dengan penetapan Hari Olahraga Nasional (HAORNAS), pemerintah juga menggelar Lokakarya Nasional tentang Pembangunan Olahraga. Kegiatan ini dihadirkan untuk menghimpun usulan dan menyusun suatu pola dasar pembangunan olahraga nasional. Pentingnya sebuah kebijaksanaan pembinaan olahraga terpadu, sehingga manfaat olahraga benar-benar kelak 
dirasakan oleh seluruh masyarakat. Hal itu pun akhirnya terumus dalam "Panji Olahraga" atau yang disebut 5P, yang antara lain sebagai berikut: 1) pelaksanaan panji olahraga; 2) pendidikan jasmani; 3) prestasi olahraga; 4) pengadaan pendidik dan pelatih; serta 5) prasarana olahraga.

Selain hal tersebut di atas, pembangunan olahraga pada waktu itu dimasukkan dalam GBHN dan Repelita IV. Akhirnya, pemerintah mencetuskan salah satu program raksasanya mengenai penetapan Jam Krida Olahraga (Keppres RI No. 17 tahun 1984). Berdasarkan Keppres tersebut, para PNS, ABRI, karyawan BUMN, BUMD, pelajar dan mahasiswa setiap hari Jumat pagi sebelum jam kerja, diharapkan melakukan kegiatan olahraga selama 30 menit. Keberadaaannya membawa angin segar, secara aktivitas pada waktu itu masyarakat senantiasa bergerak untuk berolahraga. Sehingga kemudian berkembang menjadi suatu gerakan keolahragaan nasional yang terpadu.

Dengan demikian, guna menggali dan mengungkap hal tersebut, peneliti berupaya melakukan wawancara dengan beberapa informan. Adapun hasil informasi data yang diperoleh peneliti dari hasil koding wawancara, disajikan dalam bentuk verbatim sebagai berikut:

Informasi grafis tentang rutinitas olahraga yang dilakukan masyarakat:

'Menurut Kementerian Pemuda dan Olahraga, berdasarkan data dari Badan Pusat Statistik (BPS) tahun 2018, hanya 35, 7 persen penduduk Indonesia yang aktif berolahraga. Masih hanya sekitar sepertiga lebih dari setengahnya yang hanya olahraga sekali dalam seminggu. Dengan kenyataan itu, sangat dapat dibilang jika masyarakat di Indonesia sangat kurang berolahraga' (Informan PP).

Kemudian diungkapkan oleh informan lainnya, berfokus dengan aksebilitas dan fasilitas olahraga:

'Penyediaan fasilitas olahraga dan ruang terbuka publik masih minim, di beberapa pusat kota pun masih terbatas. Di sisi lain, aksesbilitas pun masih terbatas untuk masyarakat umum, sementara itu jika untuk atlet elit yang melakukan latihan asksebilitasnya jelas berlatih'(Informan MS1).

'Di Indonesia penyediaan fasilitas dan aksesbilitas untuk berolahraga masih terbatas pada tempat, ruang, dan jarak. Ada perbedaan yang rasa rasakan, ketika studi lanjut di Australia. Di Negeri Kanguru, saya melihat masyarakatnya sangat aktif berolahraga. Dan memang di-encourage untuk terus aktif berolahraga. Kalau 
di Australia Barat, Kementerian Olahraga dan Rekreasi punya tugas spesifik: Memastikan masyarakatnya berolahraga dan punya akses ke fasilitas olahraga. 'Tugasnya bukan medali emas atau gelar juara. Melainkan untuk menyediakan fasilitas olahraga di tempat-tempat yang belum memilikinya. Bukan hanya gedung atau lapangan, tapi juga taman dan jogging track' (Informan MS2).

Selanjutnya, angka partisipasi olahraga diungkapkan informan lainnya:

'Angka partisipasi olahraga di Indonesia masih sangat rendah. Data Badan Pusat Statistik menunjukkan bahwa pada 2015, jumlah yang rutin berolahraga belum mencapai sepertiga dari total penduduk, hanya 27,61 persen penduduk Indonesia yang melakukan olahraga minimal sekali dalam seminggu. Hal ini berarti dari 100 penduduk Indonesia berumur 10 tahun ke atas, hanya sekitar 28 orang yang aktif berpartisipasi dalam kegiatan olahraga, sedangkan 72 orang lainnya tidak rutin berolahraga' (Informan AK).

'Partisipasi masyarakat Indonesia dalam berolahraga secara umum relatif masih rendah. Kondisi ini cukup memprihatinkan mengingat olahraga merupakan salah satu kegiatan yang menunjang kesehatan. Masih rendahnya partisipasi olahraga mengindikasikan bahwa masyarakat belum sepenuhnya menyadari pola hidup sehat melalui rutinitas aktivitas olahraga' (Informan AE).

Jika dicermati lebih lanjut, adanya kesamaan slogan untuk berolahraga, yang sebetulnya runtutan dasar berawal dari Sport for All untuk pertama kali dikembangkan oleh orang-orang Eropa sekitar akhir tahun 1960. Langkah pertama dalam usaha membentuk kerjasama internasional diprakarsai oleh bangsa Norwegia, yang pada tahun 1969 mengundang 10 negara Eropa di Oslo guna membicarakan kampanye "latihan" yang terkenal dengan sebutan "trim". Empat tahun kemudian langkah kedua diambil oleh Jerman Barat yang menyelenggarakan pertemuan internasional gerakan sport for all di Frankfurt dengan nama "Trim and Fitness Conference" yang dihadiri oleh para delegasi 40 negara. Adapun konsep yang mendasari sport for all dapat diinventariskan sebagai berikut: 1) Kebutuhan masyarakat; 2) Sebagai reaksi atas gerakan Olympic (Olympic Charter, 1997); 3) Penemuan kembali atas budaya dan olahraga tradisional ataupun permainan tradisional di setiap negara masingmasing; 4) Sebagai realisasi dari artikel 1 dari Piagam International tentang Pendidikan Jasmani dan Olahraga (Hak Asasi Manusia) dari UNESCO; dan 5) Kerjasama dan solidaritas internasional. Inti dari sport for all memang lebih 
mengarah pada bagaimana menggerakkan masyarakat agar memiliki budaya berolahraga secara lebih baik. Kesadaran masyarakat dalam berolahraga memiliki arti yang amat penting bagi proses berseminya kemajuan prestasi olahraga (Kristiyanto, 2016).

\section{Bergulirnya Kebijakan Olahraga Nasional}

Kebijakan yang diilustrasikan sebagai sebuah keputusan yang ditetapkan oleh pemerintah. Hal ini merupakan strategi untuk merealisasikan tujuan dari Negara dalam mengantarkan kehidupan masyarakat pada kondisi saat ini untuk kemudian memasuki proses perubahan untuk menuju peradaban masyarakat yang di cita-citakan sesuai amanat dari Pancasila, UUD 1945, Bhinneka Tunggal Ika, dan NKRI. Kebijakan pembangunan keolahragaan menjadi sebuah telaahan dalam rangka menegaskan posisi atau mencari kerangka berpikir baru bahwa sesungguhnya pembangunan di bidang keolahragaan itu dimaksudkan sebagai upaya pemerintah dalam rangka meningkatkan kualitas hidup dan kesejahteraan suatu bangsa.

Terkait hubungan kegiatan keolahragaan dengan kualitas kehidupan, yaitu bagi suatu negara yang masyarakatnya maju, modern, dan berbudaya, telah menempatkan aktivitas dan kegiatan olahraga sebagai bagian integral dalam kehidupan sehari-harinya. Jika dicermati lebih lanjut, kegiatan olahraga dipandang telah teruji mampu memberikan kontribusi secara nyata dalam meningkatkan kapasitas individu dan masyarakat untuk hidup berkualitas, sehingga dapat menyokong citra tren positif negara (Rahadian, Ma'mun, Berliana, \& Nuryadi, 2021a) dalam memberikan pelayan prima tehadap peningkatan kualitas hidup dan tingkat kesejahterannya.

Peran kegiatan olahraga memiliki berbagai fungsi yang tidak hanya berperan dalam mengembangkan kualitas kebugaran jasmani, namun erat kaitannya dengan masalah kesehatan dinamis. Namun, akan tetapi secara lebih luas olahraga dipersepsikan memiliki kompetensi yang dapat meginspirasi dan berkontribusi terhadap pembelajaran sosial dalam membangun budaya keunggulan (spirit juara). Budaya keunggulan yang sering kali diidentikan dengan 
makna dan pengabdian kepada masyarakat, bangsa, dan negara melalui partisipasi di dalam arena pertandingan atau kompetisi, baik di ajang nasional maupun internasional.

Olahraga merupakan kekuatan positif dan bersifat global yang mengajarkan nilai-nilai esensial dan universal, di sisi lain juga olahraga mengajarkan akan nilai-nilai moral dan sosial. Pembangunan keolahragaan lebih berpijak pada masyarakat luas sebagai partisipan dalam kegiatan keolahragaannya, hal ini ditujukan untuk meningkatkan kualitas hidupnya. Sudah sejak lama semboyan "memasyarakatkan olahraga dan mengolahragakan masyarakat" menjadi sebuah isu penting, tentunya hal ini menjadi salah satu andalan dalam pencapaian pembangunan keolahragaan. Dengan tujuan agar masyarakat menjadi lebih sehat, cerdas, berkepribadian, berkarakter, dan kehidupannya berkulitas agar dapat memberikan kontribusi nyata dalam mewujudkan cita-cita nasional. Dan puncaknya, pada tahun 1984, Soeharto menetapkan Keputusan Presiden (Keppres) No. 43 tahun 1984 yang memiliki tiga point penting, yaitu: pertama, memasyarakatkan olahraga dan mengolahragakan masyarakat guna mewujudkan tujuan pembangunan bangsa; kedua, meningkatkan prestasi olahraga; dan ketiga, ada kebutuhan meningkatkan usahausaha pembinaan olahraga nasional dalam arti seluas-luasnya. Adanya Kepress menunjukan bahwa pengelolaan olahraga nasional saat itu sudah di bawah norma hukum yang bersifat konkret.

\section{Bergulirnya Kementerian Pemuda dan Olahraga (Era Kepemimpinan 2004- sekarang)}

Kemenpora kembali dihidupkan, pada saat itu tampuk kepemimpinan Kemenpora dipercayakan kepada Adhyaksa Dault pada periode Kabinet Bersatu pada 21 Oktober 2004 - 22 Oktober 2009 (Kemenpora, 2004). Hidupnya kembali Kemenpora secara utuh, jelas memberikan angin segar dan harapan bagi pengembangan olahraga nasional. Selain itu, pada masa kepemimpinan Presiden SBY, Indonesia memiliki UU No. 3 Tahun 2005 tentang Sistem Keolahragaan Nasional, Peraturan Pemerintah RI No. 16 Tahun 2007 tentang Penyelenggaraan 
Keolahragaan, Peraturan Pemerintah RI No. 17 Tahun 2007 tentang penyelenggaraan Pekan dan Kejuaraan Olahraga, dan Peraturan Pemerintah No. 18 Tahun 2007 tentang Pendanaan Keolahragaan,.

Lahirnya UU No. 3 Tahun 2005 Tentang Sistem Keolahragaan Nasional membuat pemerintah memiliki payung hukum yang kuat untuk mengembangkan prestasi olahraga Indonesia. Melalui UU ini dituliskan secara rinci bahwa sistem keolahragaan nasional adalah keseluruhan aspek keolahragaan yang saling terkait secara terencana, sistimatis, terpadu, dan berkelanjutan sebagai satu kesatuan yang meliputi pengaturan, pendidikan, pelatihan, pengelolaan, pembinaan, pengembangan, dan pengawasan untuk mencapai tujuan keolahragaan nasional (UU SKN No. 3 Tahun 2005 pasal 1 ayat 3).

Dasar dari sistem keolahragaan nasional tetap berdasarkan Pancasila dan UUD 1945 dan bertujuan untuk memelihara dan meningkatkan kesehatan dan kebugaran, prestasi, kualitas manusia, menanamkan nilai moral dan akhlak mulia, sportivitas, disiplin, mempererat dan membina persatuan dan kesatuan bangsa, memperkukuh ketahanan nasional, serta mengangkat harkat, martabat, dan kehormatan bangsa (UU SKN No. 3 Tahun 2005 pasal 2 ayat 4). Hal yang terpenting adalah, dari UU ini dijelaskan tugas pemerintah dan pemerintah daerah untuk mengelola olahraga nasional. Dimana tugasnya (UU SKN No. 3 Tahun 2005 pasal 12 ayat 1 dan 2) adalah:

1. Pemerintah:

Mempunyai tugas menetapkan dan melaksanakan kebijakan serta standardisasi di bidang keolahragaan secara nasional

2. Pemerintah Daerah:

Mempunyai tugas untuk melaksanakan kebijakan dan mengoordinasikan pembinaan dan pengembangan keolahragaan serta melaksanakan standardisasi bidang keolahragaan di daerah.

Hadirnya UU Sistem Keolahragaan Nasional pada akhirnya memberikan sebuah kejelasan terkait apa dasar, fungsi, kedudukan, dan sampai dengan tugas serta wewenang pihak pemerintah untuk mengembangkan potensi olahraga yang ada. Segala kebijakan dan rencana pemerintah perihal peningkatan prestasi 
olahraga nasional akan lebih baik apabila semuanya sudah memiliki payung hukum yang jelas. Pemerintah Indonesia mengakui potensi dalam olahraga untuk mempengaruhi gerakan nasionalis sebagai prioritas awal dalam pengembangan kebijakan yang koheren (Adams, 2002). Di sisi lain, Indonesia mampu menyampaikan citra positif dari budayanya, seperti nilai gotong royong yang secara harfiah berarti berbagi beban dan untuk saling bekerja sama (Trotier, 2017).

\section{Momentum Keberhasilan Olahraga Nasional}

Sebagai catatan bahwa olahraga merupakan instrumen yang efektif untuk meningkatkan kualitas hidup bangsa. Membangun olahraga pada hakikatnya adalah membangun bangsa. Dengan demikian, olahraga perlu dikelola secara tersistem, profesional, dan menjadi komitmen kolektif. Perwujudan "keinginan menjadi masyarakat dan bangsa yang berdaya saing melalui olahraga" tidak ada cara lain, yakni dengan cara memaksimalkan hal strategis dalam mencapai tujuan pembangunan olahraga secara lengkap (Zimmermann \& Klein, 2018).

Pembinaan dan pengembangan olahraga merupakan bagian upaya peningkatan kualitas manusia Indonesia diarahkan pada peningkatan kesehatan jasmani, mental dan rohani masyarakat, serta ditujukan untuk pembentukan watak dan kepribadian, disiplin dan sportivitas yang tingi serta peningkatan prestasi yang dapat membangkitkan rasa kebanggaan nasional. Tahapan pembinaan dalam bentuk piramida adalah dimulai atlet sejak usia dini sebanyak mungkin ikut melakukan olahraga sehingga kesempatan untuk memilih calon atlet berbakat sangat terbuka. Kemudian tahap kedua pembibitan dengan proses pemanduan bakat, mngikuti kegiatan olahraga yang mengarah kepada spesialisasi, pelatihan yang intensif dengan pelatihan yang berkualitas, disiapkan kepada pembinaan yang mengarah kepada pencapaian prestasi. Selanjutnya baru pembinaan prestasi pada saat atlet berbakat mencapai usia emasnya pada cabang olahraga yang digelutinya (Koni, 2004). 
Keutamaan keberhasilan bagi seorang atlet sangatlah penting. Menjadi pahlawan olahraga mampu mengukir nama yang indah melalui perjuangan yang keras. Nama yang ditinggalkan bukanlah sekedar nama panggilan bagi dirinya saja, namun nama yang lebih bermakna yang melekat pada dirinya seperti Sang Maestro. Ketika seorang atlet mampu mengenal jati dirinya secara lebih baik, maka dapat diprediksi ia akan berupaya untuk berperan optimal di dalam hidupnya. Setiap upaya penciptaan prestasi selalu mengandung pengertian proses yang cukup lama. Upaya penciptaan prestasi bukan sesuatu yang instan, melainkan merupakan serangkaian tahapan yang dimatangkan oleh pengujianpengujian. Dengan demikian, setiap prestasi apapun bentuknya adalah hasil dari suatu kerja keras, disiplin, menghargai prestasi, dan berani bersaing (Tinaz, Turco, \& Salisbury, 2014).

\section{Pencapaian prestasi Olahraga Nasional}

Pahlawan olahraga, memiliki dampak transformatif pada olahraga (baik di dalam atau di luar bidang permainan), telah menjadi sebuah ikon dalam periode waktu tertentu (Allen, 2013). Sebelumnya pada tahun 2018, Indonesia mencatatkan sejarah terbaiknya dalam kurun waktu 10 tahun terakhir. Di mana Indonesia menempati peringkat ke 4 se-Asia dengan perolehan medali, 31 emas, 24 perak, dan 43 perunggu dengan total perolehan 98 medali. Selanjutnya didapatkan juga moment terbaik atlet pada ajang Olimpiade Tokyo 2020, Indonesia kembali ikut berpartisipasi walaupun kondisi dunia sedang mengalami pandemi (Covid-19). Alhasil, bangganya luar biasa, karena tidak semua negara yang berpartisipasi di Olimpiade dapat merasakan meraih medali emas. Yang paling anyar adalah ketika seluruh bangsa dibuat tersentak oleh pasangan ganda putri bulu tangkis, Greysia Polii dan Apriyani Rahayu yang berhasil meraih emas di Olimpiade Tokyo bertepatan dengan hari kemerdekaan Indonesia ke 76, tanggal 17 Agustus 2021. Sekaligus hadiah istimewa pada HAORNAS 2021, yang akan dilaksanakan 9 September 2021.

Sebuah kehormatan yang luar biasa dapat meraih prestasi tepat di hari yang sangat bersejarah bagi bangsa ini. Greysia Polii dan Apriyani Rahayu tidak 
hanya membawa prestasi di tingkat olahraga bagi Indonesia, tetapi pasangan bulutangkis ganda putri ini, mencatatkan sejarah sebagai pasangan ganda putri yang meraih medali emas pertama bagi Indonesia di ajang Olimpiade. Selain itu, perjuangan srikandi tersebut menghadirkan semangat persatuan dan kesatuan bangsa, yang secara langsung pasti meningkatkan rasa nasionalisme bangsa Indonesia. Selain itu, berdasarkan pencapaian prestasi disajikan data hasil perolehan medali Indonesia selama ikut berpartisipasi dalam ajang Olimpiade (1952-2020), dapat dilihat pada tabel 1.

Tabel 1. Statistik Perolehan Medali Indonesia di Olimpiade

\begin{tabular}{|c|c|c|c|c|c|c|}
\hline \multirow{2}{*}{ Tempat } & \multirow{2}{*}{ Tahun } & \multicolumn{5}{|c|}{ Perolehan Medali Olimpiade (1952-2020) } \\
\hline & & Emas & Perak & Perunggu) & Jumlah & Peringkat \\
\hline Finlandia & 1952 & 0 & 0 & 0 & 0 & - \\
\hline Australia & 1956 & 0 & 0 & 0 & 0 & - \\
\hline Italia & 1960 & 0 & 0 & 0 & 0 & - \\
\hline Jepang & 1964 & tidak ikut & tidak ikut & tidak ikut & tidak ikut & - \\
\hline Mexico & 1968 & 0 & 0 & 0 & 0 & - \\
\hline Jerman & 1972 & 0 & 0 & 0 & 0 & - \\
\hline Jerman & 1976 & 0 & 0 & 0 & 0 & - \\
\hline Rusia & 1980 & tidak ikut & tidak ikut & tidak ikut & tidak ikut & - \\
\hline Amerika & 1984 & 0 & 0 & 0 & 0 & - \\
\hline Korea Selatan & 1988 & 0 & 1 & 0 & 1 & 36 \\
\hline Spanyol & 1992 & 2 & 2 & 1 & 5 & 34 \\
\hline Amerika & 1996 & 1 & 1 & 2 & 4 & 41 \\
\hline Australia & 2000 & 1 & 3 & 2 & 6 & 38 \\
\hline Yunani & 2004 & 1 & 1 & 2 & 4 & 48 \\
\hline China & 2008 & 1 & 1 & 4 & 6 & 42 \\
\hline Inggris & 2012 & 2 & 1 & 0 & 3 & 60 \\
\hline Brazil & 2016 & 1 & 2 & 0 & 3 & 46 \\
\hline Jepang & 2020 & 1 & 1 & 3 & 5 & 55 \\
\hline & Total & 8 & 14 & 15 & 37 & 59 \\
\hline
\end{tabular}

Momentum HAORNAS sebagai Pemberian Penghargaan bagi Pelaku dan Insan Olahraga Nasional

Pemberian penghargaan merupakan bentuk apresiasi dari pemerintah terhadap insan olahraga yang telah berjuang mengibarkan bendera merah putih pada ajang tertinggi dalam dunia olahraga. Pemerintah secara legal telah menetapkan melalui Peraturan Presiden Republik Indonesia Nomor. 44 Tahun 2014 tentang Pemberian Penghargaan Olahraga, yang selanjutnya diperkuat dengan Keputusan Menteri Pemuda dan Olahraga Nomor. 65 Tahun 2019 
tentang Pemberian Penghargaan bagi Pelaku Olahraga Berprestasi pada Peringatan Hari Olahraga Nasional. Penghargaan olahraga yang dapat diberikan kepada pelaku olahraga, organisasi olahraga, lembaga pemerintah/swasta, dan perseorangan yang berprestasi dan/atau berjasa dalam memajukan olahraga berbentuk: a) tanda kehormatan; b) kemudahan; c) beasiswa; d) pekerjaan; e)kenaikan pangkat luar biasa; f) asuransi; g) kewarganegaraan; h) warga kehormatan; i) jaminan hari tua; j) kesejahteraan; atau k) bentuk penghargaan lain. Para pejuang olahraga ini telah rela mencurahkan waktu, tenaga, dan segalanya yang diperlukan dalam rangka mengharumkan nama dan kehormatan bangsa di depan negara-negara lain yang ikut serta dalam ajang tersebut.

\section{KESIMPULAN}

Kesimpulan yang dapat diambil dalam penelitian ini, antara lain sebagai berikut:

1. Pencanangan Hari Olahraga Nasional (HAORNAS) sebagai sebuah bukti history of sport di Indonesia, yang merupakan dasar pijakan olahraga di tanah air.

2. Hari Olahraga Nasional (HAORNAS) sebagai representasi gerakan "sport for all" yang mengarah kepada pergeseran perspektif dari paradigma 'pengembangan olahraga' menjadi 'pengembangan melalui olahraga' sebagai upaya meningkatkan kualitas kehidupan masyarakat.

3. Hari Olahraga Nasional (HAORNAS) merupakan salah satu indikator pencapaian dari instrumen pembangunan keolahragaan, yang dalam hal ini bertujuan meningkatkan kualitas hidup masyarakat Indonesia.

4. Peringatan Hari Olahraga Nasional (HAORNAS) sebagai sebuah momentum dalam upaya menumbuhkan budaya olahraga yang dilaksanakan secara koheren, terpadu, dan berkesinambungan. Selain itu, sebagai wujud pemberian penghargaan bagi pelaku dan insan olahraga nasional yang telah 
berjuang mengibarkan bendera merah putih pada ajang olahraga internasional.

5. Hari Olahraga Nasional (HAORNAS) membawa pesan positif untuk mengajak seluruh elemen masyarakat Indonesia untuk rutin melaksanakan Gerakan Ayo Olahraga dengan prinsip murah, mudah, meriah, massal dan manfaat.

\section{REFERENSI}

Adams, I. (2002). Pancasila: Sport and the building of Indonesia - Ambitions and obstacles. International Journal of the History of Sport, 19(2-3), 295-318. https://doi.org/10.1080/714001759

Allen, D. (2013). National heroes: Sport and the creation of icons. Sport in History, 33(4), 584-594. https://doi.org/10.1080/17460263.2013.850782

Brown, D. J., Arnold, R., Reid, T., \& Roberts, G. (2018). A Qualitative Exploration of Thriving in Elite Sport. Journal of Applied Sport Psychology, 30(2), 129-149. https://doi.org/10.1080/10413200.2017.1354339

Chen, T., Hui, E. C. M., Lang, W., \& Tao, L. (2016). People, recreational facility and physical activity: New-type urbanization planning for the healthy communities in China. Habitat International, 58, 12-22. https://doi.org/10.1016/j.habitatint.2016.09.001

Creswell1, J. (2015). Research Design Qualitative, Quantitative, and Mixed Method.

de Bosscher, V., Shilbury, D., Theeboom, M., van Hoecke, J., \& de Knop, P. (2011). Effectiveness of national elite sport policies: A multidimensional approach applied to the case of Flanders. European Sport Management Quarterly, 11(2), 115-141. https://doi.org/10.1080/16184742.2011.559133

Funahashi, H., De Bosscher, V., \& Mano, Y. (2015). Understanding public acceptance of elite sport policy in Japan: a structural equation modelling approach. European Sport Management Quarterly, 15(4), 478-504. https://doi.org/10.1080/16184742.2015.1056200

Gulbin, J. P., Croser, M. J., Morley, E. J., \& Weissensteiner, J. (2013). An integrated framework for the optimisation of sport and athlete development : A practitioner approach An integrated framework for the optimisation of sport and athlete, (August), 37-41. https://doi.org/10.1080/02640414.2013.781661

Hong, F., Wu, P., \& Xiong, H. (2005). Beijing Ambitions: An Analysis of the Chinese Elite Sports System and its Olympic Strategy for the 2008 Olympic Games. The International Journal of the History of Sport, 22(4), 510-529. https://doi.org/10.1080/09523360500126336 
Hu, X. (Richard), \& Henry, I. (2017). Reform and maintenance of Juguo Tizhi: governmental management discourse of Chinese elite sport. European Sport Management Quarterly, 17(4), 531-553. https://doi.org/10.1080/16184742.2017.1304433

Kemenpora. (2004). Rencana Strategis Kementerian Pemuda dan Olahraga Tahun 2004-2009. Jakarta: Kementerian Pemuda dan Olahraga RI Kidd, B. (2008). A new social movement: Sport for development and peace, 0437. https://doi.org/10.1080/17430430802019268

KONI. (2014). Rencana Strategis Komite Olahraga Nasional Indonesia Tahun 2014-2019. Jakarta: Komite Olahraga Nasional Indonesia Pusat RI

Kristiyanto, A. (2016). Formula khas budaya dan daya saing olahraga untuk bergegas menuju pentas prestasi dunia. Seminar Nasional Refleksi Prestasi Dan Budaya Olahraga Dalam Perspektif Ilmu Keolahragaan Yang Inovatif, 1-21.

Lutan, R. (2005). Indonesia and the Asian Games: Sport, nationalism and the "new order." Sport in Society, 8(3), 414-424. https://doi.org/10.1080/17430430500249175

Ma'mun, A. (2019). Governmental Roles in Indonesian Sport Policy: From Past to Present. International Journal of the History of Sport, 36(4-5), 388-406. https://doi.org/10.1080/09523367.2019.1618837

Menteri Pemuda dan Olahraga RI. (2017). Peraturan Menteri Pemuda dan Olahraga No. 18 Tahun 2017 tentang Gerakan Ayo Olahraga.

Menteri Pemuda dan Olahraga RI. (2019). Keputusan Menteri Pemuda dan Olahraga No. 65 Tahun 2019 tentang Pemberian Penghargaan bagi Pelaku Olahraga Berprestasi pada Peringatan Hari Olahraga Nasional.

Molan, C., Kelly, S., Arnold, R., \& Matthews, J. (2019). Performance Management: A Systematic Review of Processes in Elite Sport and Other Performance Domains. Journal of Applied Sport Psychology, 31(1), 87-104. https://doi.org/10.1080/10413200.2018.1440659

Peraturan Pemerintah. (1984). Republik Indonesia, Keputusan Presiden No. 43 Tahun 1984 tentang Komite Olahraga Nasional.

Peraturan Pemerintah. (1985). Republik Indonesia, Keputusan Presiden No. 67 Tahun 1985 tentang Hari Olahraga Nasional.

Peraturan Pemerintah. (2007). Republik Indonesia, Peraturan Pemerintah No. 16 Tahun 2007 tentang Penyelenggaraan Keolahragaan.

Peraturan Pemerintah. (2007). Republik Indonesia, Peraturan Pemerintah No. 17 Tahun 2007 tentang penyelenggaraan Pekan dan Kejuaraan Olahraga.

Peraturan Pemerintah. (2007). Republik Indonesia, Peraturan Pemerintah No. 18 Tahun 2007 tentang Pendanaan Keolahragaan.

Peraturan Pemerintah. (2014). Republik Indonesia, Peraturan Presiden Republik Indonesia No. 44 Tahun 2014 tentang Pemberian Penghargaan Olahraga 
Peraturan Pemerintah. (2017). Republik Indonesia, Peraturan Presiden No. 95 Tahun 2017 tentang Peningkatan Prestasi Olahraga Nasional.

Rahadian, A., \& Ma'mun, A. (2018). Kebijakan Olahraga dalam Pemerintahan Lokal: Sebuah Penelitian dalam Merumuskan Rancangan Induk Pembangunan Olahraga Nasional. Prosiding Seminar Pendidikan JasmaniFPOK UPI, (Sport Policy), 1-12. Retrieved from https://www.researchgate.net/publication/342260670

Rahadian, A., Ma'mun, A., Berliana, \& Nuryadi. (2021a). 2018 Asian Games Success: Policies for the Development of Indonesian Elite Athlete. Maenpo, 11(1), 1-12. https://doi.org/https://doi.org/10.35194/jm.v11i1.1278

Rahadian, A., Ma'mun, A., Berliana, \& Nuryadi. (2021b). Successful Elite Sport Policies: Indonesia at The 2018 Asian Games. Juara: Jurnal Olahraga, 6(2), 288-303. https://doi.org/https://doi.org/10.33222/juara.v6i2.1327

Republik Indonesia. (2005). Undang-Undang Republik Indonesia No. 03 Tahun 2005 tentang Sistem Keolahragaan Nasional. Jakarta: Presiden Republik Indonesia.

Sotiriadou, P. (2013). Sport development planning: The Sunny Golf Club. Sport Management Review, 16(4), 514-523. https://doi.org/10.1016/j.smr.2012.09.002

Sotiriadou, P., \& De Bosscher, V. (2018). Managing high-performance sport: introduction to past, present and future considerations. European Sport Management Quarterly, https://doi.org/10.1080/16184742.2017.1400225

$18(1)$

Tinaz, C., Turco, D. M., \& Salisbury, P. (2014). Sport policy in Turkey. International Journal of Sport Policy, 6(3), 533-545. https://doi.org/10.1080/19406940.2014.893247

Trotier, F. (2017). Changing an image through sports events: Palembang's success story. Asia Pacific Journal of Sport and Social Science, 6(1), 3-18. https://doi.org/10.1080/21640599.2016.1276252

Veal, A. J. J. (2011). Planning for leisure, sport, tourism and the arts: goals and rationales. World Leisure Journal, 53(2), 119-148. https://doi.org/10.1080/04419057.2011.580553

Zhang, H., Hong, F., \& Huang, F. (2018). Cultural imperialism, nationalism, and the modernization of physical education and sport in China, 1840-1949. International Journal of the History of Sport, 35(1), 43-60. https://doi.org/10.1080/09523367.2018.1500460

Zhouxiang, L. (2011). Sport, nationalism and the building of the modern Chinese nation state (1912-49). International Journal of the History of Sport, 28(7), 10301054. https://doi.org/10.1080/09523367.2011.563635

Zimmermann, T., \& Klein, M. (2018). The contribution of league systems in 
individual sports to the development of high-performance sport in Germany, 4742. https://doi.org/10.1080/16184742.2017.1387800 